
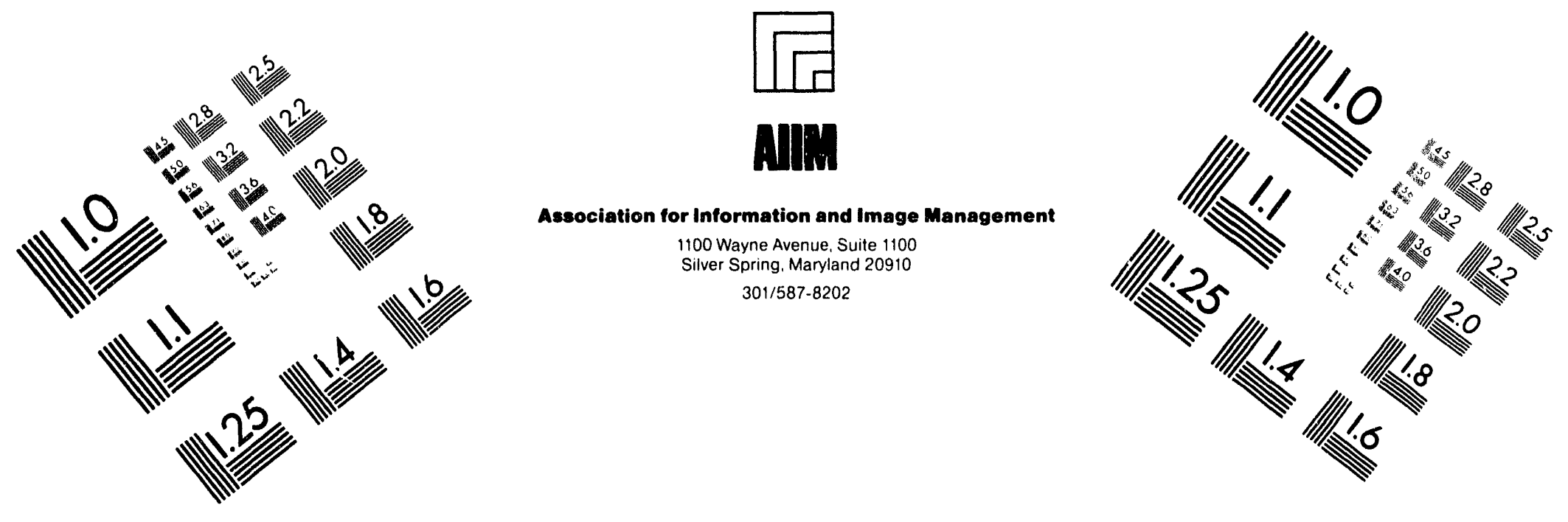

\title{
Centimeter
}

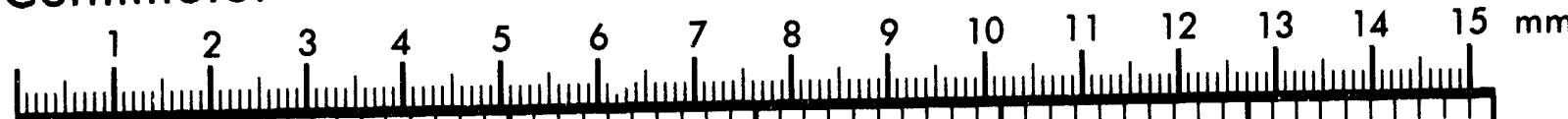

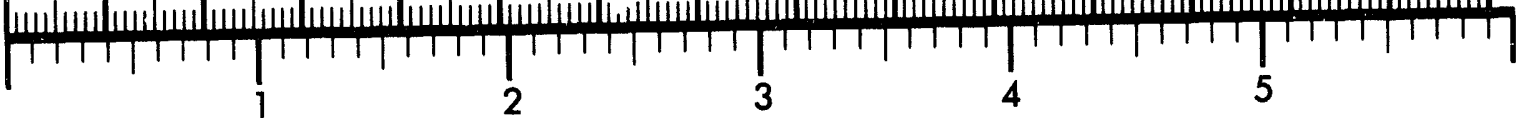
Inches
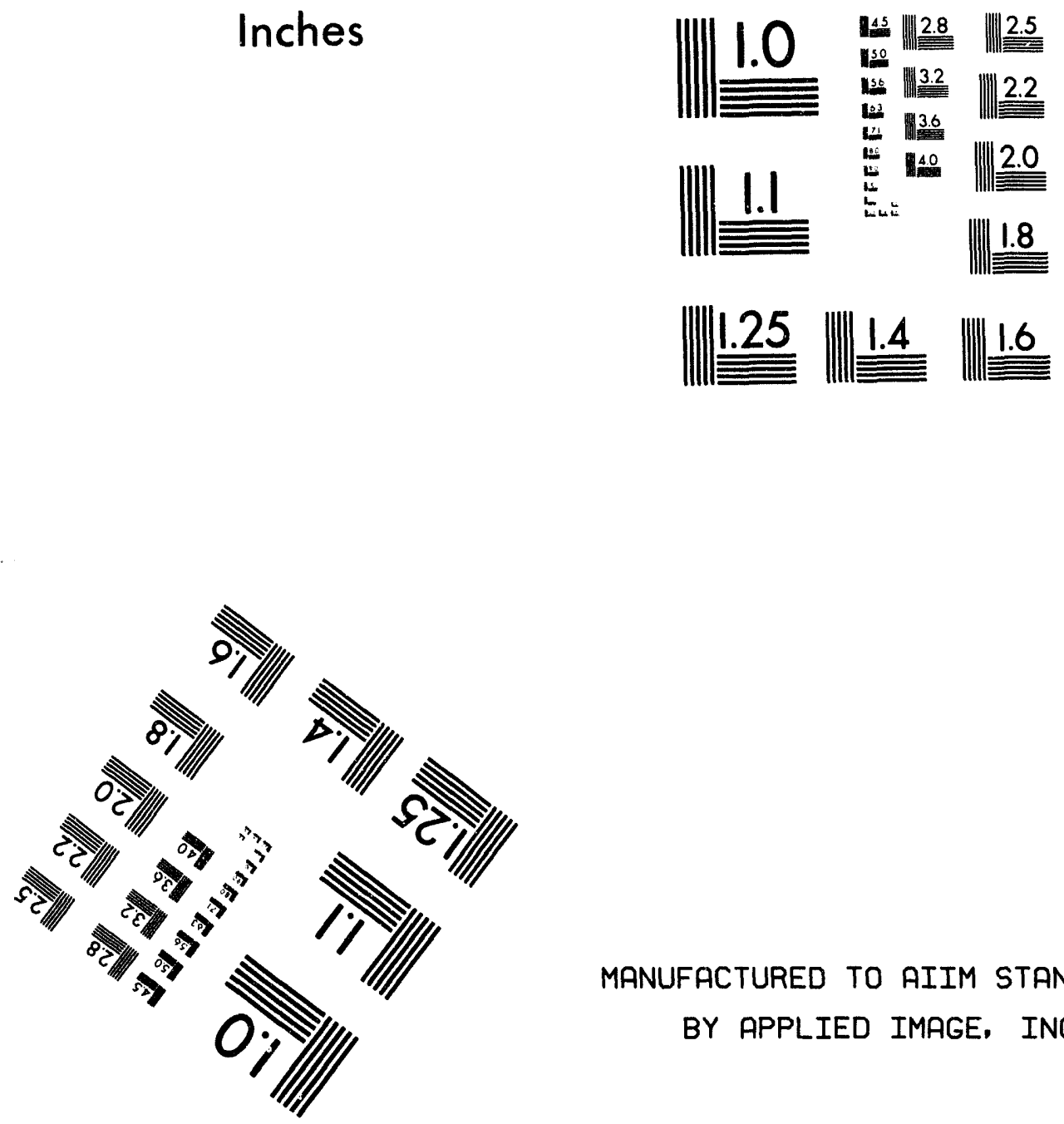

MANUFACTURED TO AIIM STANDARDS BY APPLIED IMAGE, INC.

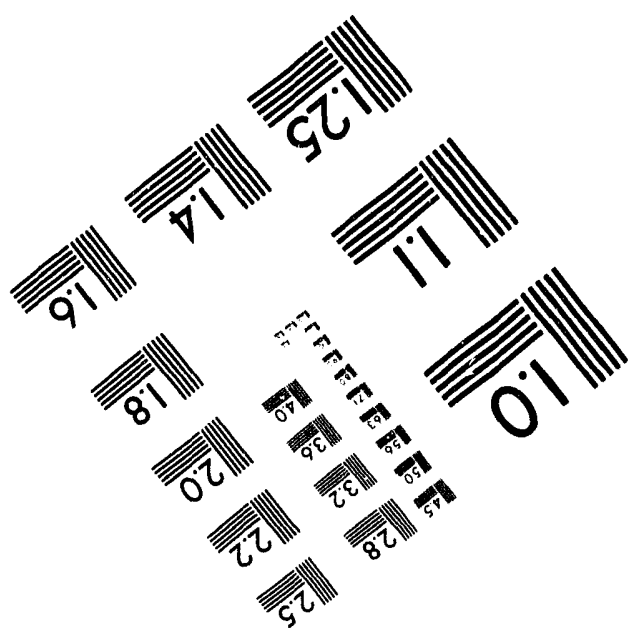



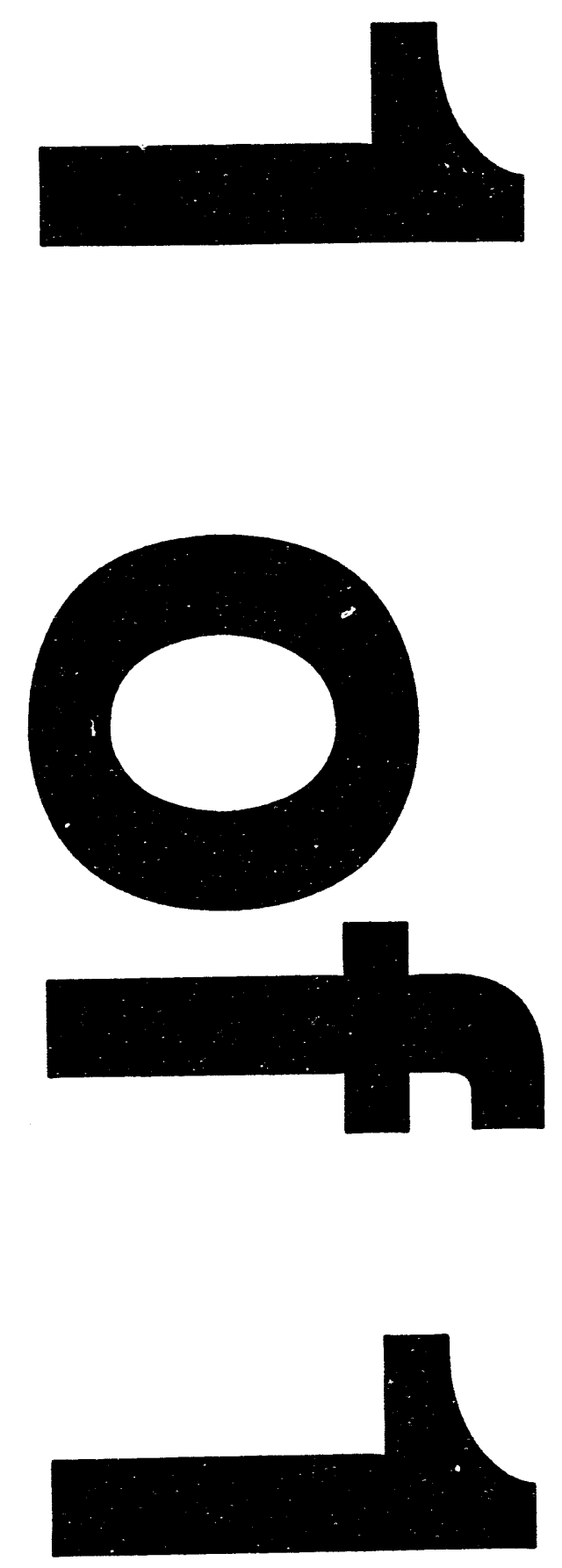


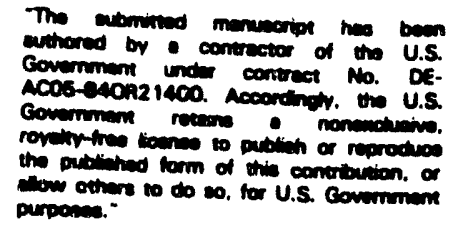

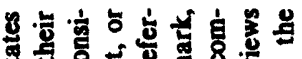

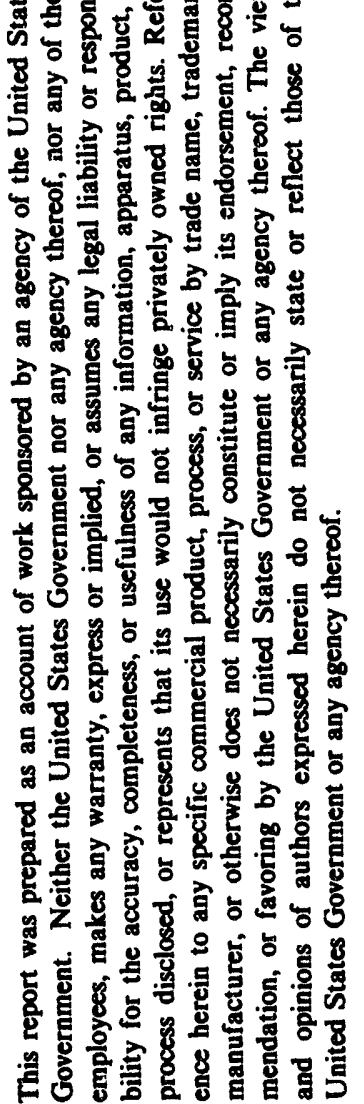

\section{USE OF HYDROPYROLYSIS.MS TO PROBE THE HYDROCRACKING OF DIPHENYLALKANE LINKAGES IN THE SOLID STATE}

\author{
S.D. Brown (1), O. Sirkecioglu (1), K. Isnaail (1), J. Andresen (1), C. E. Snape (1) \\ A.C. Buchanan DI (2) and P.P. Britt (2) \\ (1) University of Strachclyde. Department of Pure \& Applied Chemistry, \\ (2) Chemistry and Analyoical Sciences Division, Oak Ridge National \\ Laboratory, Oak Ridge. Tennessee 37831, USA
}

Keywords: hydropyrolysis, resites, silica immobilised substrates

\section{INTRODUCTION}

Diphenylalkanes have been exicasively used as model substrates to probe the free radical mechanisms involved in C.C bond cleavage reactions during coal liquefaction (1). However, the fact that the macromolecular structure in coals is undoubledly subject to highly restricted motion suggests innuitively that free radical pathways are likely to be somewhat different from those encountered in the vapour phase. Indeed this has been confirmed by the use of silicaimmobilised substrates where bimolecular reaction steps are significanily pernurbed for diphenylalkanes compared to the corresponding vapour phase reactions (2.5). For pyrolysis srudies, these model substrates have the inherent advantage that they do not soften and so remain in the reactor. Thus, immobilised substrates have considerable potendal for modeling coal pyrolysis phenomena, particularly the effects of high bydrogen pressures (hydropyrolysis).
Indeed, for immobilised benzene, the SiO.C bond linking the substrate to the surface is reasonably stable and does not cleave until above $500^{\circ} \mathrm{C}$ (peak maximum at $\mathrm{SSO}^{\circ} \mathrm{C}$ ) with 150 bar hydrogen pressure (0). For immobilised dipheaylmethane (DPM), it was demonstrated previously that the use of 150 bar hydrogen pressure and a sulphided Mo catalyst both reduced the peak evolution comperanures for benzene and coluene clearly dernonstrating their separate contributions to promoting C-C bond cleavage (0).

An aliemative class of materials to immobilised substrates that should prove equally as suitable for modeling pyrolysis phenomena are cured phenolformaldebyde resins. These offer the option of incorporating a wide variety of hydrocarbon and heteroatomic mojeties into the basic pheoolic macromolecular strucrure. A series of co-resites were recently prepared from phenol and, as the second component, a series of sulphur-containing precursors, namely $2 \cdot$ hydroxy dibenzothiophene, $p$-hydroxydiphenylsulphide, thydrox yphenylbenzylsulphide and 4 hydroxythioanisole (7). These precursors have also been used previously for the preparation of silica-immobilised substates (8) which, together with the resites have been used as calibrants in temperanure programnied reduction (7.9).
To investigate the hydrocracking of diphenylalkane linkages in the solid state with the additional aim of elucidating how the nature of a paricular substrate might influence the reaction pathways, hydropyrolysis experiments with oo-lide mass spectrometric analysis have been conducted on silica-immobilised substrates, phenolic resites and a polystyrene-divinylbenzene nenwork using hydrogen
pressures of $S$ and 150 bar.

\section{EXPERIMENTAL}

Substrales and their synthesis The dipheoylmethane co-resites were prepared using the procedure described by Bar and Aizenshial (10) which was used previously for the sulphur-containing resites $(n$. A total phenol to formaldehyde mole ratio of $1: 2.5$ was used with sodium hydroxide as catalyst for the condensation reaction, a mole ratio of 0.1 with respect to phenol being employed. The mole ratio of pheool to the monohydroxydiphenylalkanes (diphenylechane and propane) was $3: 1$ to ensure that a reasonably high degree of crosslinking was achieved in the initial resoles. DSC indicated that co-resoles prepased with a mole ratso of only $1: 1$ melted to a considerable extent in the temperanre range, 
$250-2800 \mathrm{C}$. The co-resites were cured in an oven purged with nitrogen gas at a icmperanure of $200 \times$ C. Solid state 13C NDIR was used to monitor the conversion of the ether/alcohol functional groups to mithylene bridges dunng curing. Cross polarisation/magic-angle spinning (CPMAS) spectra were obtained using a Bruker MSL100 instrument operaing at $25 \mathrm{MHz}$ for carbon.

The silica-imnobilised samples were prepared from the appropriate phenol as previously described (2-5). The loadings of the diphenylmethane (DPMI) and dipheaylethane (DPE) substraics invesugated here are summarised below. These were determined by hydrolysing the substrates with base and conducting GC analysis of the tesultant phenols which were silylated.

$\begin{array}{ll}\text { Diphenylmethane, normal } & \text { Loading, mmol } \mathrm{g} \cdot 1 \\ \text { Dideuterated diphenylmethane }\left(\mathrm{PhCD}_{2} \mathrm{Ph}\right) & 0.45 \\ \text { Co-attached diphenylmethane/letralin } & 0.31 \\ \text { Dipheoylethane } & 0.2810 .18 \\ & 0.60\end{array}$

The polystyrene-divinylbenzene (PS-DVB) sample used, XAD-4 is commercially available.

Hydroprolysis-MS Decails on the high pressure system have been repored previously $(7,8,11)$. Hydrogen pressures of 5 and 150 bar were used with a heating rate of $5^{\circ} \mathrm{C} / \mathrm{min}$ over the range $100.600^{\circ} \mathrm{C}$. Typically, between 0.2 and $0.3 \mathrm{~g}$ of the resite (paricle size range of ca $0.1 .1 .0 \mathrm{~mm}$ ) was mixed with $2.3 \mathrm{~g}$ sand. The volarile species evolved were detected on-line using a quadrupole mass spectrometer (VG Sensorlab, 0-300 a.m.u).

\section{RESULTS AND DISCUSSION}

Cielinkares Figure 1 shows the evolution of benzene, toluene and cresol at 150 bas pressure from a normal pheool resite not containing a second consoinent. The benzene evolving at high temperanure (TMax of $5500 \mathrm{C}$ ) is considered to arise mainly from the hydrodeoxygenation of phenol, cresols and xylenols. The cresol profile and, 10 a lesser extent, thut for $\mathrm{m} / \mathrm{z} 91$ (this probably comprises fragment ions of 108) contais peaks at ca 5500C which are arubuted to the primary cleavage of the methylede bridges. Figure 2 compares the benzene evolution profiles at 150 bar pressure from the immobilised DPM substrates. As found previously (6), the profiles can be resolved iato two broad components. The higher temperature one $(530-6000 \mathrm{C})$ is consisteot with that ancicipated for cleavage of the SiO.C bond in surface-immobilised benzene. Toluene is similarly formed following the prior bydrogenolysis of the C.C linkages in diphenylmethane according to the reaction scheme:

$$
. \mathrm{SiOPhCH} 2 \mathrm{Ph}+2 \mathrm{H}_{2} \ldots \rightarrow \mathrm{SiOPhH}+\mathrm{PhCH}_{3}+\cdot \mathrm{SiOPhCH}_{3}+\mathrm{PhH}
$$

The $T_{\max }$ of $480-5000 \mathrm{C}$ of the lower componeat at is very similar to that for the resite suggesting that the additional free radical chemisny that occurs in the resite does not significantly promote the cleavage of the methylene bridges at high hydrogen pressure.

The similar intensities of the $\mathbf{m} / \mathbf{2} 78$ and 79 incensives iodicates that, as anticipated, extensive scrambling of the methylepe deuteriums has occurred. The co-attachment of tetralis had little effect on the benzene and coluene evolution profiles both at low and high pressure (Figure 2). The greater $\mathrm{n} / 278$ intensity observed for the co-attached DPM is probably attributable to the likely cuntributions from tetralin breakdown products. No naphehalene w'as detected indicauing that hydrogen transfer had not occured to a significant extent.

Ca-linkages Figures 3 and 4 show the benzene and toluene profiles from thie immobilised DPE at low and high pressure and Figure 4 compares the toluene evolusion profiles for the immobilised DPE and DPE-containing resite at 150 bar. Given that the relative response factor of benzene to toluene is $c a 3.1$, the coluene concendration is much the higher at low pressure. This is consistent with 
all the low pressure isuthermal work on DPE (ooch free and immobilised) (1.2) where there is linle evidence of cleaving the aryl-C boods. At high pressure, this is cluary no longer the case with benzede concentration being considerably higher (ca 30\% of that for toluene, Figures 3 and 4). Increasing the bydrogen pressure has also given rise to a slightly lower $T_{\text {MnX }}$ for benzene and coluene (430 cf $4500 \mathrm{C}$ ) and. as for DPM, resulted in much more benzene evolving above $5000 \mathrm{C}$ indicating the role of hydrogen pressuse in circumventing char-fonning reaction pathways.

By comparison with Figure 2, the contribution below $480 \mathrm{CC}$ in the profile for the resite can be ascribed to cleavage of the DPE linkage. Although the high remperature contributions from the remainder of the resite dominate the trace, the low temperanure region matches fairly closely that for the immobilised DPE with an initial $T_{\text {MAX }}$ occurring at ca $430 \circ \mathrm{C}$.

Ca-linkapes Figure $S$ shows the virually identical tolvene and ethyl beazene evolution profiles from the PS-DVB at 5 and 150 bar pressure. The concentration of styrede evolving a low pressure was comparable to that of ethylbenzede. Al low pressure, a sharp TMax occurs at $450^{\circ} \mathrm{C}$ with smaller amounts of tolvene and ethylbenzene evolving at higher temperatures from secondary reactions. At high pressure, the evolution profiles are considerably broader. The volatiles begio to evolve at $3200 \mathrm{C}$ but the broad peak in the cemperanure range is the supersition of more than one distinct reaction pathway Further, much greater quantites evolve above $470 \mathrm{C}$ which again is indicative the role of hydrogen pressure in circumventing char-forming reaction pachways.

Figure 6 compares the evolution profile of toluene form the PS-DVB and DPP. containing resite. The uraces are very similar indicatiog again that, with high hydrogen pressures, the primary scission of the C-C bonds in diphenylalkanes is fairly independeat of the aature of the substrate.

\section{CONCLUSIONS}

The results have indicated increasing the hydrogen pressure reduces the extent of retrogressive chemistry for all the model substrates investigated. The primary pyrolyoic event $a$ high hydrogen pressure, as characterised by the evolution of benzene, toluene and ethylbenzede/styreac, occurs at virtually the same cempcrature for a given alkane linkage in the different substrates used. The $C_{2}$ and $C_{3}$ linkages investigated are cleaved at ca $50-1000 \mathrm{C}$ lower than their $C_{1}$ counterparts. The pyrolysis of immobilised dipbenylmethane appears to be largely unaffected by the co-attachment of tetralin.

\section{ACKNOWLEDGEMENTS}

The research was supported at (i) the University of Strathelyde by the Science \& Enginceriog Research Council (Grant No. GR/J/08997) and the Deparment of Trade \& Lodustry and at (ii) Oak Ridge National Laboratory by the Division of Chemical Sciences. Office of Basic Energy Systems, US DoE (Contract No. DEACOS-840R21 400 with Marin Marietta Energy Systems, Inc.).

\section{REEERENCES}

1. M.L. Poutsma. Energy Fuels, 1990, 4(2), 113 and references therein.

2. A.C. Buchanan III. T.D.J. Dunstan, E.C. Douglas and M.L. Poustma, L Am. Chem Soc. 1986, 108, 7703.

3. A.C. Buchanan II and C.A. Biggs. LOte Chem, 1989, 54, 517.

4. A.C. Buchanan MI. P.F. Britl and MI.L Pousma Preor. Am. Chem SOc. Div. Fuel Chem, 1990, 35(1), 217.

5. P.F. Brill and A.C. Buchanad III, LOre. Cocm. 1991, 56. 6132.

6. S.C. Mitchell, C.J. Lafferry, R. Garcia, K. Ismail, C.E. Soape, A.C. Buchanan III. P.F. Britt and E. Klavelter. Energv \& Fusls. 1993. 7, 331

7. K.Ismail, G.D. Love, S.C, Mitchell, S D. Browin and C.E. Snape, Prepe Amer Chem Soc Div, Euel Chsm, 1994, 39(2), 1691.

8. S.C. Mitchell, C.J. Lafferty, R. Garcia K. Ismail, C.E. Snape, A.C. Buchanan IU, P.F. Britl and E. Kiaverter, Bungl Amer Chem. Soc Div. Euel Chem. 1992, 37(4), 551. 
9. K. Ismail, R. Garcia S.C. Mitchell, C.E. Soape, A.C. Buchanan III, P.F. Brith D. Franco and S. Yperman, Broculag3 Inc Conf an Coal Science. Banff. September 1993.

10. H. Bar and Z. Aizenshtat, L. Apal Apol Pyrolysis. 19, 1991, 265.

11. C.J. Lafferty, S.C. Mitchell, R. Garcia and C.E. Snape. Euel, 1993, 72. 367.

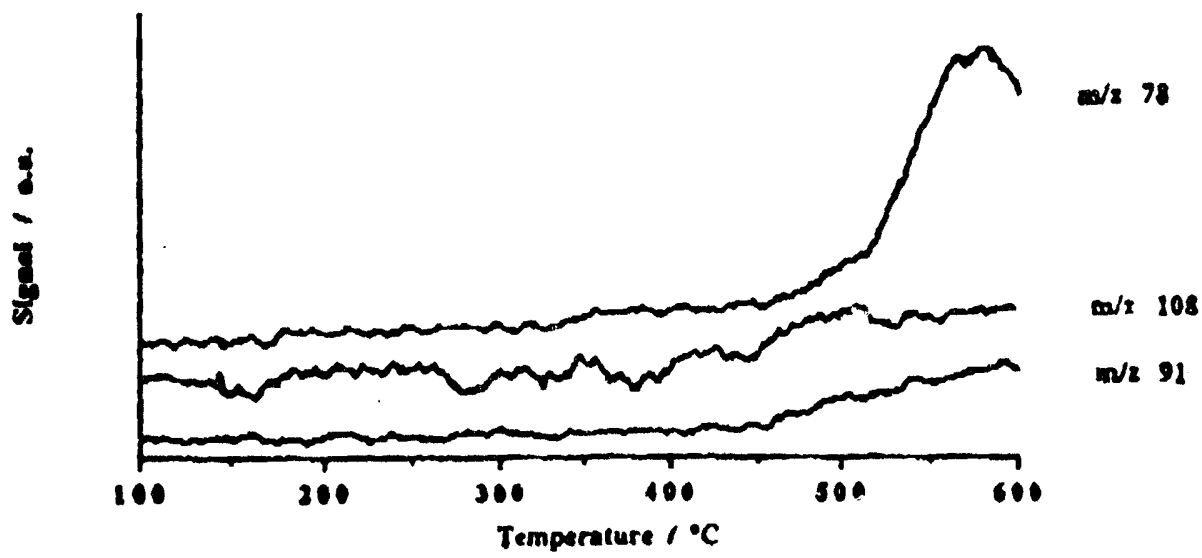

Figure 1. Hydropyrolysis evoludion profiles of benzene, toluene and cresol from the normal phenolic sesite under 150 bar $\mathrm{H}_{2}$

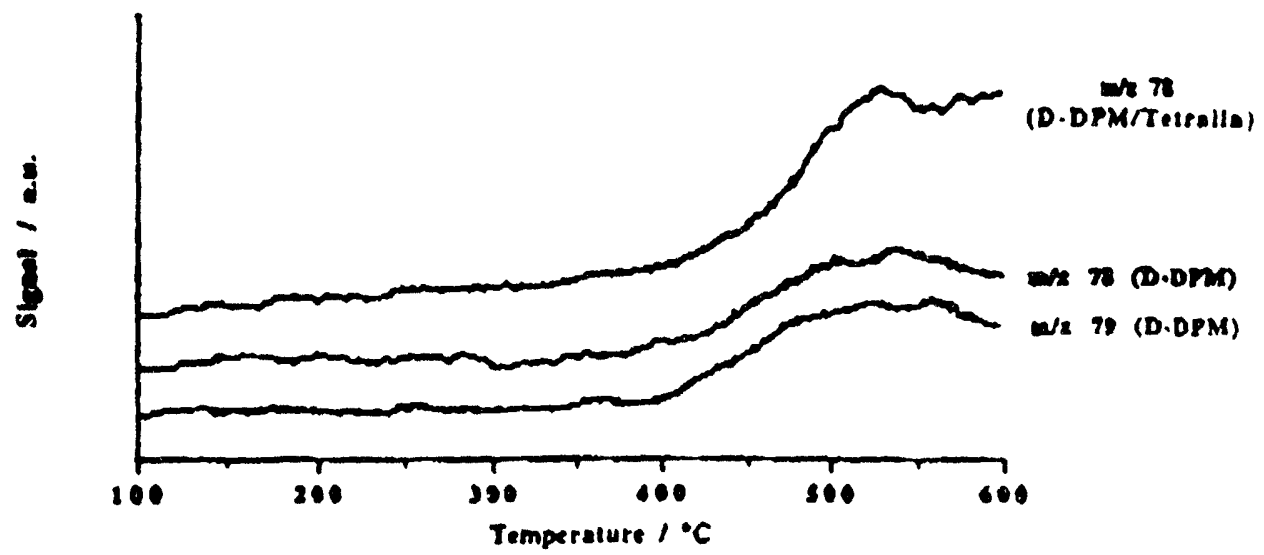

Figure 2. Evolution profiles of benzene from silica-immobilised di-deuterated diphenylmethane and silica-inumobilised ci-deuterated diphenyimethane with co-attached tetralin under 150 bar $\mathrm{H}_{2}$

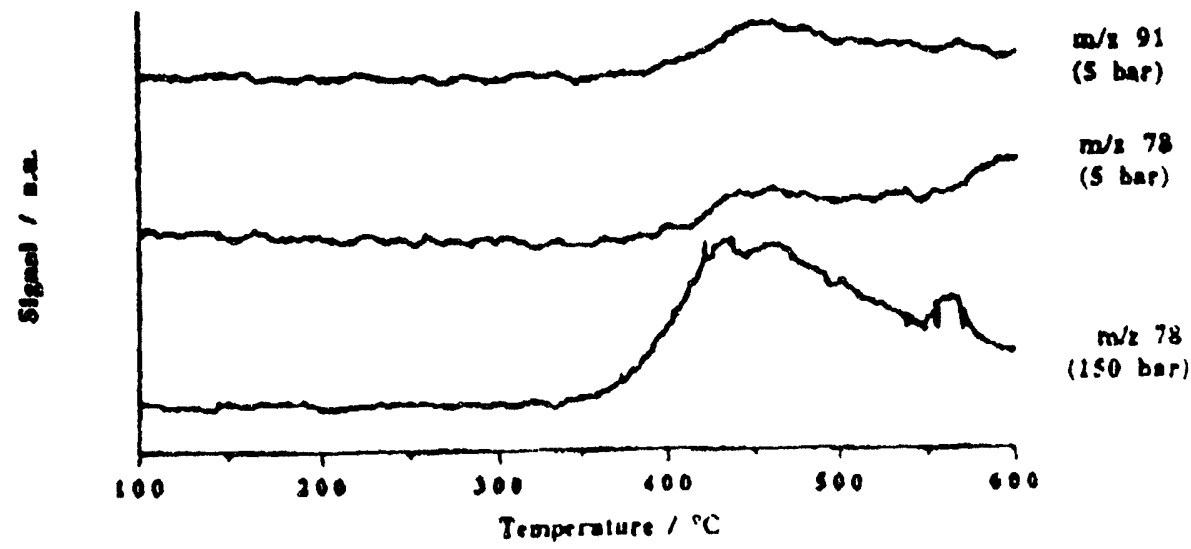

Figure 3. Hydropyrolysis-m.s. profiles of silica.immobilised dsphenylethane undor 5 and 1.50 bar $\mathrm{H}$ : 


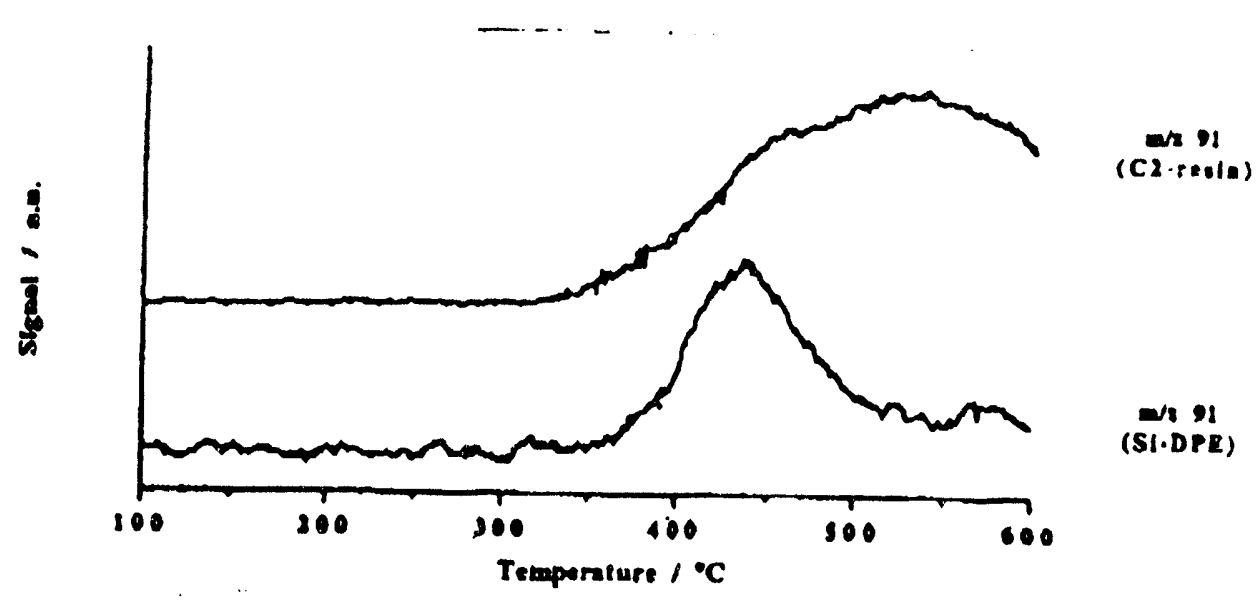

Figure.4. Toluene evolunion profiles from the diphenylethane phenolic resite and the silica-immobilised diphenylethane under 150 bar $\mathrm{H}_{2}$

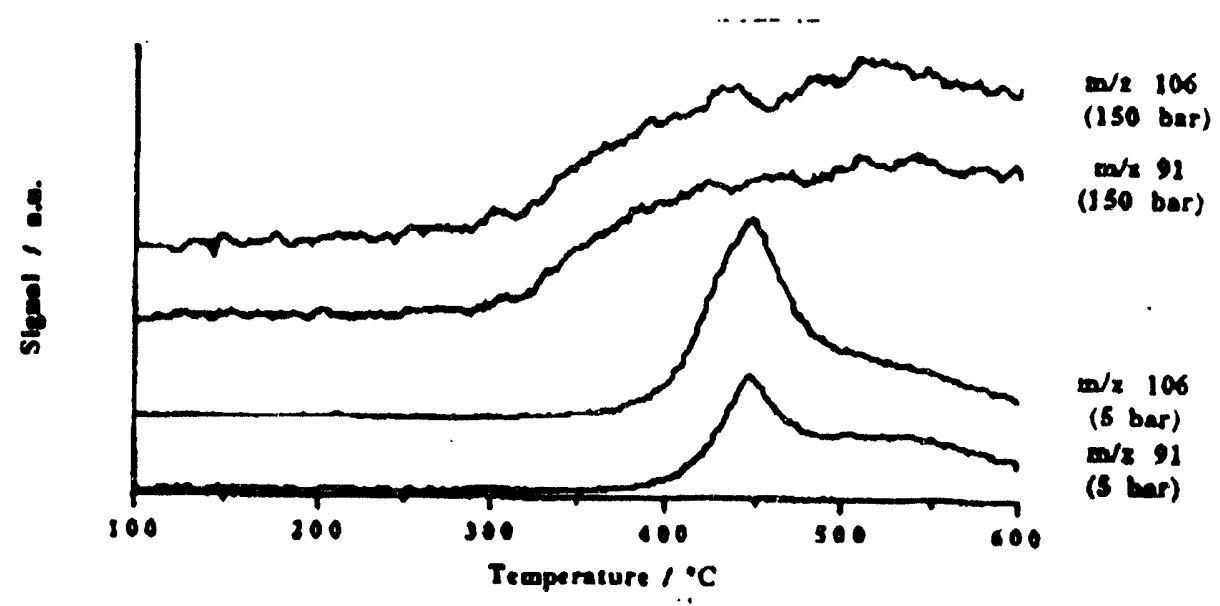

Figure 5. Evolution profiles of toluene and ethylbenzene from the PS-DVB under 5 and 150 bar $\mathrm{H}_{2}$

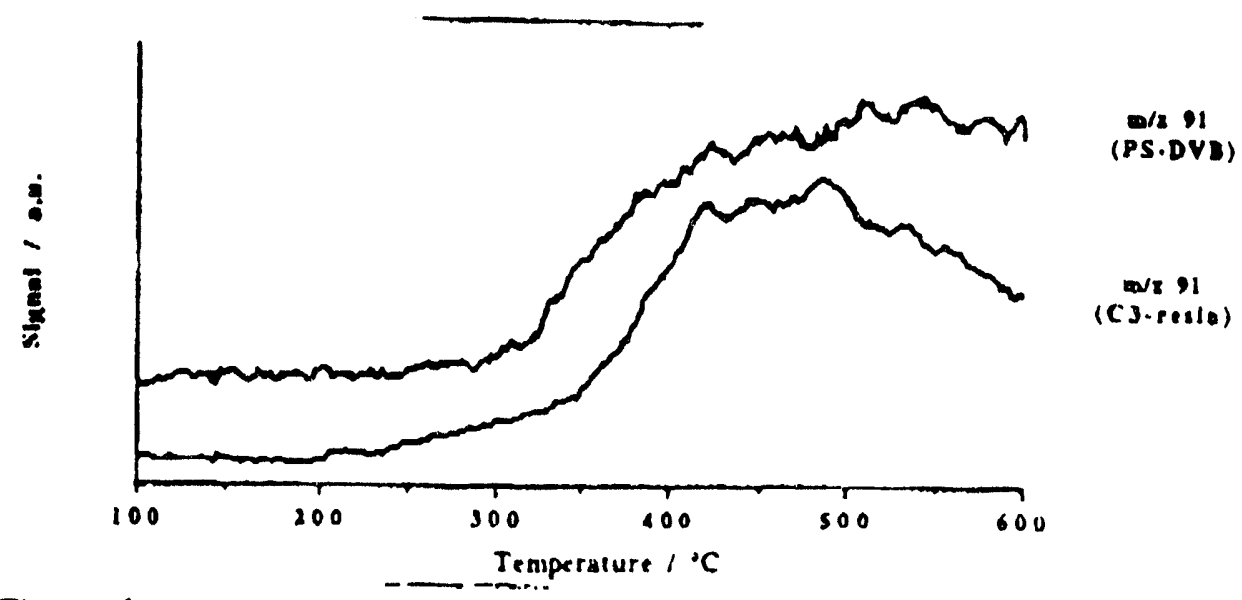

Figure 6. A comparison of the toluene evolution profiles from the PS-DVB and the diphenylpropane phenolic resice under 150 bar $\mathrm{H}_{2}$ 

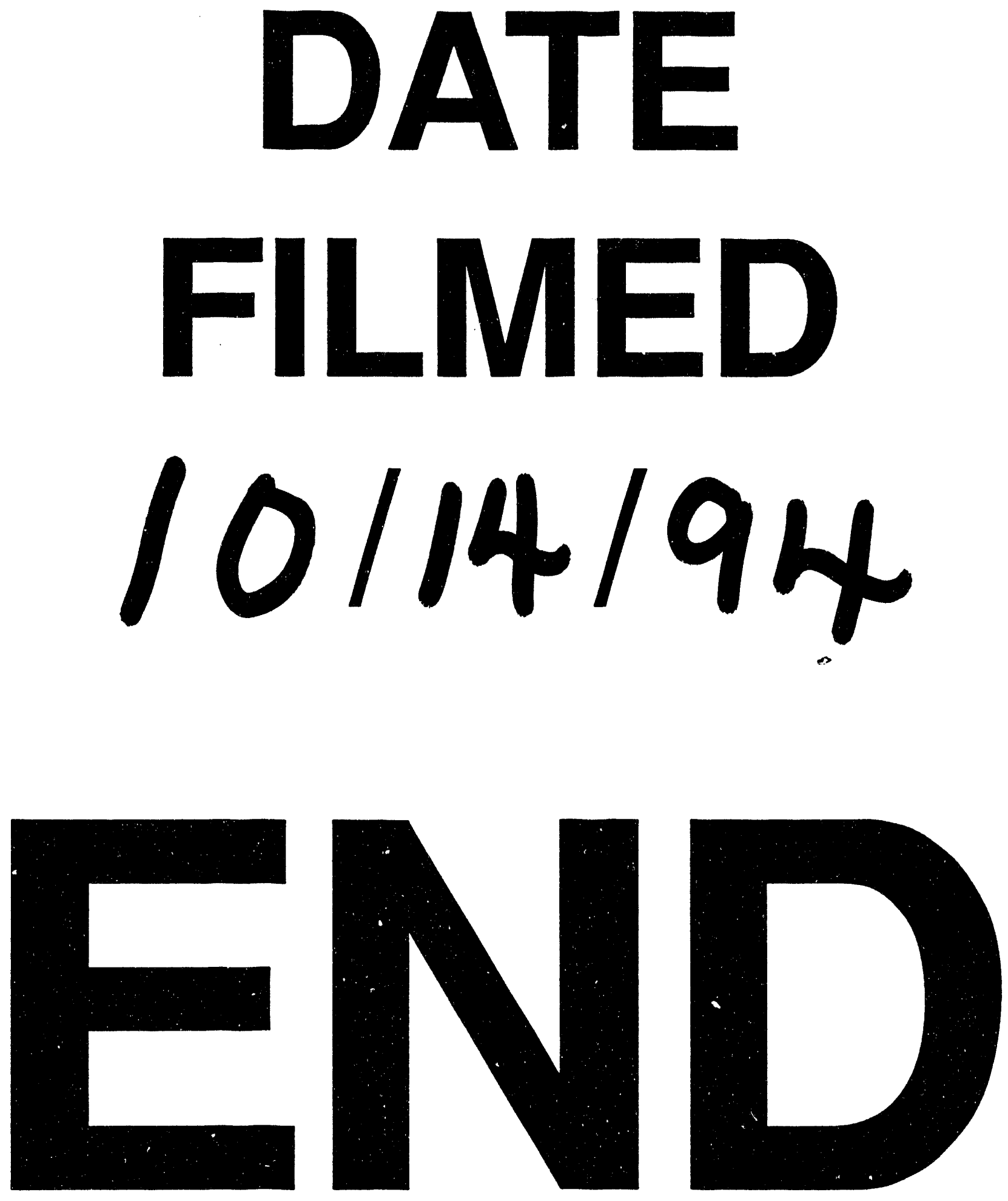
